\title{
An improved estimate of lithospheric thickness based on a reinterpretation of tilt data from Pleistocene Lake Algonquin
}

\author{
DETLEF WOLF \\ Department of Physics, University of Toronto, Toronto, Ont., Canada, M5S IA7 \\ Received May 8, 1984 \\ Revision accepted November 13, 1984
}

\begin{abstract}
A reinterpretation of relative-uplift data associated with the deformed strandline of Pleistocene Lake Algonquin is presented. The new analysis is based on a dynamic model that allows for the finite rate of retreat of the Laurentide ice sheet and the viscous relaxation of the Earth's mantle. Attention is also paid to the effects of the shape of the load profile on the interpretation. In the context of this model the thickness of the lithosphere is constrained to be not more than $85 \mathrm{~km}$. This value is based on the assumption of a model ice sheet with a parabolic cross section. If the load has a sharper edge, a thickness of $110 \mathrm{~km}$ is consistent with the data. These revised values slightly exceed Walcott's original estimate. They are, on the other hand, distinctly lower than the value of $200 \mathrm{~km}$, which has recently been inferred by Peltier for the thickness of the North American lithosphere. The relations between the different estimates are briefly discussed. It is suggested that a reconciliation of the estimates may require that effects caused by geoidal perturbations be included in future analyses of strandline tilt.
\end{abstract}

Nous présentons un nouvelle interprétation des donnés sur le soulèvement relatif au Pléistocène associé avec les changements produits sur les lignes de rivage du lac Algonquin. Cette nouvelle analyse des données repose sur un modèle dynamique qui tient compte d'un taux fini de retrait de la nappe glaciaire Laurentide et de la relaxation visqueuse du manteau de la Terre. En plus, on considère dans l'interprétation des calculs les effets de la forme du profil de charge. Dans le cadre de cette interprétation, l'épaisseur de la lithosphère ne peut dépasser $85 \mathrm{~km}$. Cette épaisseur limite est fondée sur l'hypothèse que nous sommes en présence d'une nappe glaciaire de coupe transversale parabolique. Si la charge est répartie plus étroitement, une épaisseur de $110 \mathrm{~km}$ est compatible avec les résultats. Ces valeurs révisées sont légèrement plus élevées que les estimations originales de Walcott. Elles sont cependant significativement inférieures à l'épaisseur déduite par Peltier de $200 \mathrm{~km}$ pour la lithosphère de l'Amérique du Nord. Nous discutons brièvement des relations entre les diverses valeurs estimées. Nous croyons qu'un rapprochement des valeurs estimées est possible si on tient compte dans les analyses futures des modifications des lignes de rivage des effets engendrés par les perturbations géoïdales.

Can. J. Earth Sc1. 22, $768-773$ (1985)

[Traduit par le journal]

\section{Introduction}

At the end of the Pleistocene glaciation the margin of the Laurentide ice sheet in Canada was flanked by a number of major proglacial lakes. Some of their shorelines are preserved and have been mapped and dated by geologists. Detailed studies have been carried out in the regions of Pleistocene lakes Agassiz and Algonquin, which existed in Manitoba and the Great Lakes region of eastern North America, respectively.

In general, the glacial shorelines show a characteristic pattern of deformation. Today their iceward ends are tilted upward relative to the portions of the same shoreline farther away from the ice margin. This has been interpreted as a consequence of deglaciation-induced uplift of the Earth's surface.

A particularly well preserved glacial shoreline is the Algonquin shoreline in the region of present-day lakes Michigan and Huron. The relative-uplift data have been compiled by Broecker (1966). Basic to his interpretation of the data was, however, the assumption of a lithosphere of negligible strength. Broecker's analysis is therefore mainly of historical interest.

The first, and apparently only, attempt to analyse the tilt data of Lake Algonquin in terms of an Earth model that is consistent with modern geodynamical concepts is Walcott's $(1970 a)$ interpretation. Using the model of an elastic lithosphere overlying an inviscid substratum, he estimated the strength of the lithosphere. His estimate may be expressed as a flexural rigidity value of $6 \times 10^{24} \mathrm{~N} \mathrm{~m}$, with a range from $3 \times 10^{24}$ to $2 \times 10^{25} \mathrm{~N} \mathrm{~m}$ (Walcott $1970 b$ ).

One of the main premises in Walcott's $(1970 a)$ interpretation was the assumption of static equilibrium both at the time of deposition and at the time of observation of the strandline. Then the presently observed strandline simply "mirrors" the deformation of the Earth's surface during the time of glaciation.

Walcott's (1970a) interpretation has been questioned by several authors. The main point in their criticism has been precisely Walcott's adoption of a static Earth model (e.g., Nakiboglu and Lambeck 1982; Peltier 1984). As these authors argued, a static model would be acceptable only if the relaxation time of the mantle were small compared with the time interval elapsed since the deposition of the Algonquin strandline. Since the uplift of the deglaciated region of Canada is still continuing, the dominant relaxation time must be at least of the order of $10 \mathrm{ka}$. This, however, is also approximately the age of the strandline.

A different, but equally important, aspect of Walcott's (1970a) analysis not hitherto discussed is the sensitivity of the inferred lithospheric thickness to the shape of the load. As shown by Brotchie and Silvester (1969), the deflection of the Earth's surface is strongly affected by the load profile. Unfortunately, both the shape of the glacial load and the deglaciation history are not known very precisely. This ignorance therefore imparts additional degrees of freedom to the interpretation.

In the following, a reanalysis of the relative-uplift data of Pleistocene Lake Algonquin will be proposed and discussed. The interpretation will be based on a dynamic model that allows for the finite rate of ice retreat and the viscous relaxation of the Earth's mantle. Particular attention will be paid to the sensitivity of the inferred lithospheric thickness to $(a)$ the shape of the load profile and $(b)$ the time of deglaciation relative to the time of deposition of the strandline. The modifications of the estimates by effects caused by $(i)$ the viscosity structure of the mantle, (ii) the compressibility of the lithosphere, (iii) 


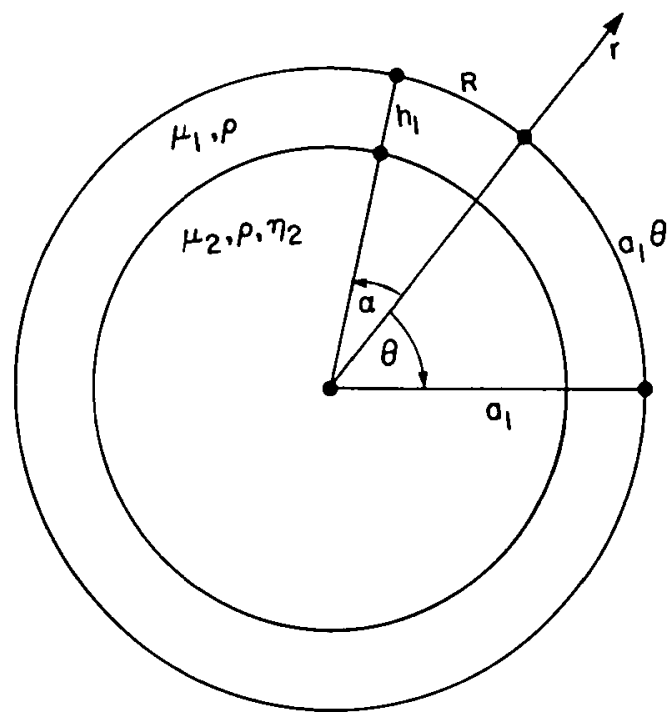

FiG. 1. Parameters of Earth model.

irregularities in the shape of the Laurentide ice sheet, and (iv) perturbations of the geoid will be discussed at the end.

\section{Theoretical model}

The Earth model underlying our study is composed of an elastic spherical shell surrounding a uniform Maxwell continuum (Fig. 1). For a general analysis of the response to superimposed loads the reader is referred to Wolf (1984b), where the analytical solution is derived and numerical examples are discussed. In order to simplify the theory, the Earth model is incompressible. This simplification has no practical consequences for the relaxation of the viscoelastic mantle (Wolf 1985). Corrections for the compressibility of the lithosphere are readily applied and will be discussed later.

For the rigidity of the elastic shell and viscous mantle $\mu_{1}=0.67 \times 10^{11} \mathrm{~N} \mathrm{~m}^{-2}$ and $\mu_{2}=1.45 \times 10^{11} \mathrm{~N} \mathrm{~m}^{-2}$ have been chosen, respectively. The viscosity of the Earth's mantle is fixed to $\eta_{2}=10^{21} \mathrm{~Pa}$ s. This is in accordance with recent estimates for the upper mantle (e.g., Cathles 1975; Peltier and Andrews 1976; Peltier 1982). The density of the two layers of the Earth model is $\rho=3320 \mathrm{~kg} \mathrm{~m}^{-3}$. This choice insures correct surface deflections in isostatic equilibrium, which for loads of large diameter is essentially independent of the elastic parameters of the lithosphere and largely determined by the nearsurface density contrast.

The Laurentide ice sheet will be modelled as an axisymmetric cap load, and several load profiles will be discussed. All cross sections are approximated by stacks of superimposed square-edged loads. The decay of the ice sheet is simulated by a stepwise reduction of both the radius and the thickness of the load. Mathematically this is realized by a convolution of the model deglaciation history with the Earth model's impulse response.

According to Paterson (1981, pp. 153-184), the equilibrium profile of a perfectly plastic ice sheet is given by

$$
h_{0}(\theta)=\left\{\begin{array}{cl}
h_{0}(0)(1-\theta / \beta)^{1 / 2} & 0 \leq \theta<\beta \\
0 & \beta \leq \theta \leq a, \pi
\end{array}\right.
$$

Parameter $a_{1}$ denotes the radius of the Earth; $\theta$ is the angular distance from the load axis; $\beta=R / a_{1}$ is the angular radius of

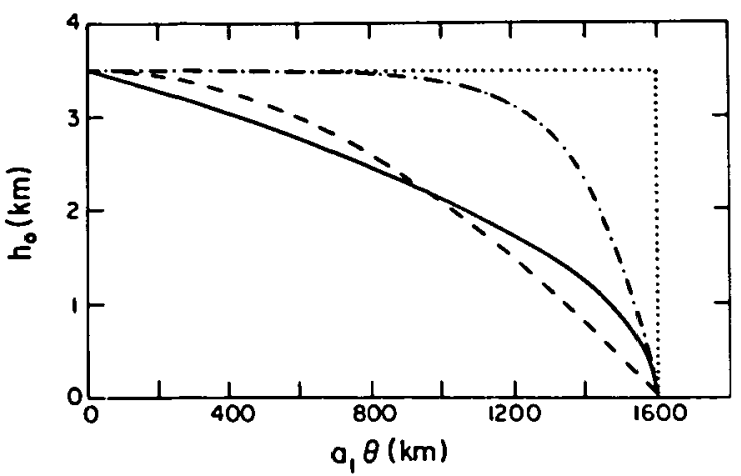

FIG. 2. Thickness $h_{0}$ of load as function of distance $a_{1} \theta$ from load axis for square-edged (dotted), exponential (dot-dashed), parabolic (solid), and quadratic (dashed) load profiles.

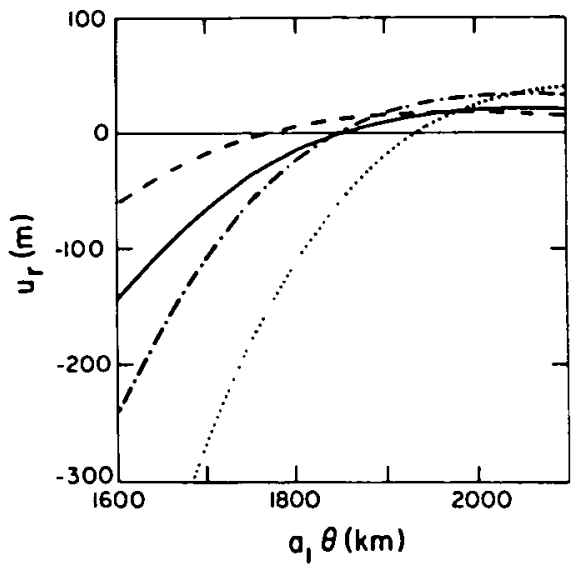

FIG. 3. Radial surface displacement $u_{\mathrm{r}}$ as function of distance $a_{1} \theta$ from load axis for square-edged (dotted), exponentıal (dot-dashed). parabolic (solid), and quadratic (dashed) profiles of Fig. 2: results apply to $h_{1}=100 \mathrm{~km}$ and $\eta_{2}=0$.

the load; and $h_{0}$ is the load thickness (Fig. 1). This will be called the parabolic profile (Fig. 2).

Walcott $(1970 a)$ has chosen an exponential load profile in order to model the Laurentide ice sheet. The cross section is given by the formula

$$
\text { [2] } h_{0}(\theta)=\left\{\begin{array}{cl}
h_{0}(0)(1-\exp [-b(\beta-\theta)]) & 0 \leq \theta<\beta \\
0 & \beta \leq \theta \leq a, \pi
\end{array}\right.
$$

Walcott has taken $a_{1} / b=180 \mathrm{~km}$. As he shows, this choice approximates the parabolic load profile of an ice sheet of 450 $\mathrm{km}$ maximum closely. On the scale of the Laurentide ice sheet, which had a radius of about $1600 \mathrm{~km}$ and a maximum thickness of at least $3.5 \mathrm{~km}$, the exponential profile is, however, characterized by a much sharper edge (Fig. 2).

A profile that, compared with the parabolic profile, has an enhanced thickness close to the load axis but a substantially reduced thickness near the edge is realized by the quadratic function

[3] $h_{0}(\theta)=\left\{\begin{array}{cl}h_{0}(0)\left[1-\left(\frac{\sin \theta}{\sin \beta}\right)^{2}\right] & 0 \leq \theta<\beta \\ 0 & \beta \leq \theta \leq a_{1} \pi\end{array}\right.$

Figure 3 compares the radial surface deflection due to the three load types with that associated with a square-edged cap 
TABLE 1. Parameters of load model

\begin{tabular}{ccc}
\hline \hline $\begin{array}{c}t \\
(\mathrm{ka})\end{array}$ & $\begin{array}{c}R \\
(\mathrm{~km})\end{array}$ & $\begin{array}{r}h_{0}(0) \\
(\mathrm{km})\end{array}$ \\
\hline$-\infty-0$ & 1600 & 4.00 \\
$0-1$ & 1400 & 3.74 \\
$1-2$ & 1200 & 3.46 \\
$2-3$ & 1000 & 3.16 \\
$3-4$ & 800 & 2.83 \\
$4-5$ & 600 & 2.45 \\
$5-6$ & 400 & 2.00 \\
$6-7$ & 200 & 1.41 \\
$7-\infty$ & 0 & 0.00 \\
\hline
\end{tabular}

load,(see Fig. 2). Since proglacial lakes were located in front of the ice margin, the comparison has been confined to the region peripheral to the load. The cap loads have a radius of $R=1600 \mathrm{~km}$ and an axial thickness of $h_{0}(0)=3.5 \mathrm{~km}$. It is further assumed that the Earth model has attained equilibrium under the superimposed load (inviscid limit). The thickness $h_{1}$ of the elastic lithosphere has been fixed at $100 \mathrm{~km}$.

As mentioned previously, Walcott (1970a) assumed that the presently observed uplift of the Algonquin strandline is equal to the (negative of the) radial deflection of the Earth's surface in the inviscid limit. From Fig. 3 it is evident that the cross section of the ice sheet enters critically into the theoretical uplift. Steeper ice margins result in steeper uplift curves. Since an increase in the thickness of the lithosphere has the opposite effect (e.g., Wolf 1984b), we anticipate a pronounced trade-off between profile shape and lithospheric thickness. In the following we will be interested in finding an upper bound on lithospheric thickness. Therefore only the parabolic and exponential ice profiles will be considered.

If we drop the assumption of isostatic equilibrium at the times of deposition and observation of the Algonquin shoreline, we must take into account both the viscosity of the Earth's mantle and the finite rate of retreat of the ice sheet. Irrespective of the unknown details of the unloading event, it appears well established that the Laurentide ice sheet reached its maximum earlier than $10 \mathrm{ka}$ before present (BP) and had essentially disappeared by about 5 ka BP (e.g., Prest 1969; Paterson 1972).

In the absence of detailed information, the deglaciation history of Table 1 will be adopted. For times $t<0$ the Earth model is assumed to be in equilibrium under the weight of a parabolic ice sheet with a $1600 \mathrm{~km}$ radius and a $4 \mathrm{~km}$ axial thickness. For model times $t>0$ a deglaciation history is superimposed on this deformation. As shown in the table, the radius is reduced in eight steps of $200 \mathrm{~km}$, such that the load has vanished at $t=7 \mathrm{ka}$. Theoretical arguments (Paterson 1981, pp. 154-155) suggest that the ratio $h_{0}^{2}(0) / R$ remains constant in [1], which applies for the equilibrium profile of a perfectly plastic ice sheet. This results in a steepening of its slope near the edge with decreasing load radius (Table 1).

The age of the Algonquin strandline is probably between 10 and $11 \mathrm{ka}$ (Broecker 1966). In the present calculations three different times of deposition of the strandline are proposed: 0 , 1 , and $2 \mathrm{ka}$. The time of observation of the strandline is usually 12 ka.

A further unknown is the location of the ice margin relative to Lake Algonquin during the deposition of the strandline. Walcott $(1970 a)$ constrained this position to be north of the northernmost record of the Algonquin strandline but south of
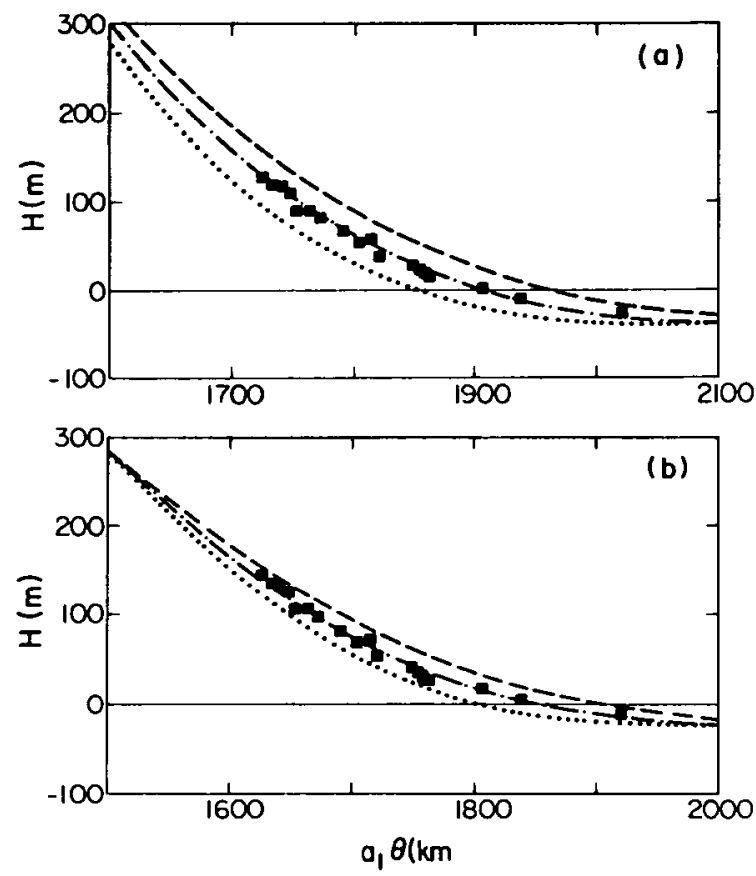

FIG. 4. Relative-uplift data (after Chapman 1954) and theoretical prediction $H$ as function of distance $a_{1} \theta$ from load axis for (a) exponential profile and $h_{1}=100 \mathrm{~km}$ (dotted), $h_{1}=125 \mathrm{~km}$ (dotdashed), or $h_{1}=150 \mathrm{~km}$ (dashed); or for $(b)$ parabolic profile and $h_{1}=75 \mathrm{~km}$ (dotted), $h_{1}=100 \mathrm{~km}$ (dot-dashed), or $h_{1}=125 \mathrm{~km}$ (dashed); results apply to isostatic equilibrium.

the Fossmill outlet, through which the lake was drained in its later stages. Although it is clear that Lake Algonquin did not exist below the ice, the Fossmill outlet, which is approximately $70 \mathrm{~km}$ north of the nearest beach level, could also have been blocked by moraines. Then the ice margin could have been located farther north. In the following analysis the position of the ice margin at the time of deposition of the strandline will only be constrained to be north of the northernmost strandline record.

\section{Data analysis}

A representative subset of the complete data set compiled by Broecker (1966) is included in Figs. 4 and 5. The subset was originally published by Chapman (1954) and portrays the observed relative uplift of the Algonquin strandline projected on a line normal to the ice front. The figures also include several theoretical predictions. If $u_{\mathrm{r}}\left(t_{1}\right)$ denotes the radial surface deflection at the time $t_{1}$ of deposition and $u_{\mathrm{r}}\left(t_{2}\right)$ the corresponding quantity at the time $t_{2}$ of observation of the strandline, the uplift of the strandline is simply given by

\section{[4] $H=u_{\mathrm{r}}\left(t_{2}\right)-u_{\mathrm{r}}\left(t_{1}\right)$}

For purposes of comparison we first consider a model similar to that used by Walcott $(1970 a)$ and assume isostatic equilibrium at the time of deposition and at the time of observation of the strandline. The theoretical-uplift curves of Fig. $4 a$ are for the exponential profile [2], with $R=1600 \mathrm{~km}, h_{0}(0)=4 \mathrm{~km}$, and $a_{1} / b=180 \mathrm{~km}$, which is essentially the shape used by Walcott. The steep slope of the uplift curve belonging to the exponential load (see also Fig. 2) must be compensated by a lithosphere of approximately $125 \mathrm{~km}$ thickness. In Fig. $4 b$ the load profile is assumed to be parabolic, with $R=1600 \mathrm{~km}$ and 

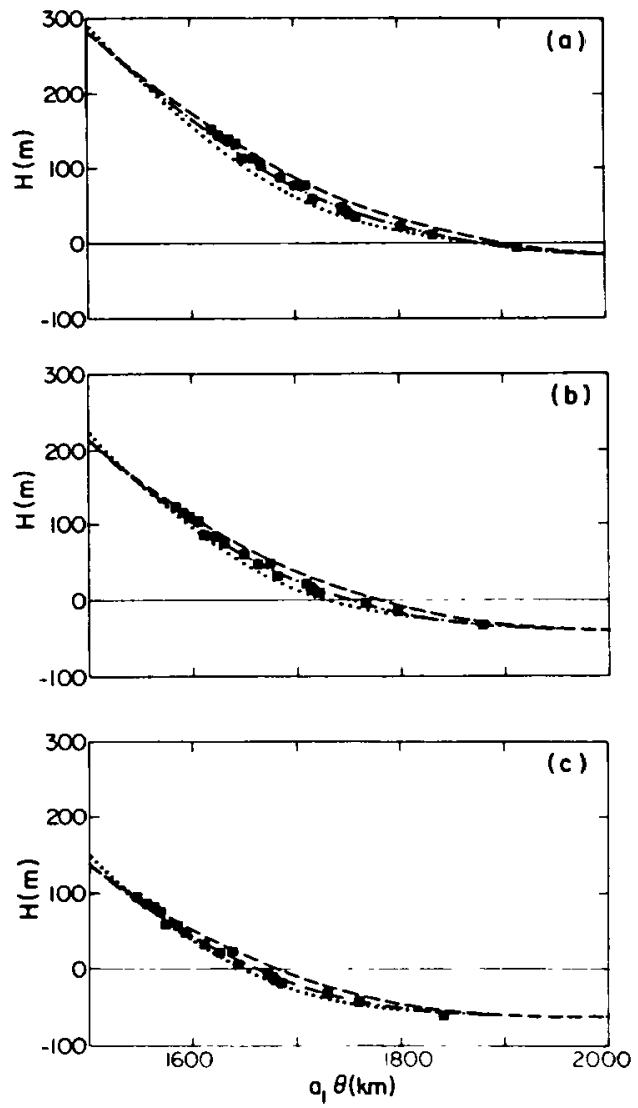

FiG. 5. Relative-uplift data (after Chapman 1954) and theoretical prediction $H$ as function of distance $a_{1} \theta$ from load axis and for (a) $t_{1}=0$ and $h_{1}=50 \mathrm{~km}$ (dotted), $h_{1}=75 \mathrm{~km}$ (dot-dashed), or $h_{1}=100 \mathrm{~km}$ (dashed); for (b) $t_{1}=1 \mathrm{ka}$ and $h_{1}=35 \mathrm{~km}$ (dotted), $h_{1}=60 \mathrm{~km}$ (dot-dashed), or $h_{1}=85 \mathrm{~km}$ (dashed); or for (c) $t_{1}=2$ $\mathrm{ka}$ and $h_{1}=25 \mathrm{~km}$ (dotted), $h_{1}=50 \mathrm{~km}$ (dot-dashed), or $h_{1}=75$ $\mathrm{km}$ (dashed); results apply to load model of Table 1 and $t_{2}=12 \mathrm{ka}$.

$h_{0}(0)=4 \mathrm{~km}$ as before. Now a thickness of close to $100 \mathrm{~km}$ is required by the data.

Figure 5 applies to the deglaciation history of Table 1. In Fig. $5 a$ the deposition of the strandline is assumed to be at $t_{1}=0$; it is observed at $t_{2}=12 \mathrm{ka}$. Thus, no uplift takes place before the deposition of the strandline, but uplift is incomplete at the time of observation. The best fitting lithospheric thickness is $75 \mathrm{~km}$. In Fig. $5 b$ it is assumed that the strandline has formed $11 \mathrm{ka} \mathrm{BP}$. A small portion of the total uplift has therefore taken place between the initiation of deglaciation at $t=0$ and the existence of Lake Algonquin at $t_{1}=1 \mathrm{ka}$. The flattening of the theoretical-uplift curve is reflected in the figure where the best fit is attained for the reduced thickness of $60 \mathrm{~km}$. In Fig. $5 c t_{1}=2 \mathrm{ka}$ has been chosen. According to Table 1 this means that the ice sheet had already retreated by several hundred kilometres and was situated substantially north of the Fossmill outlet during the existence of Lake Algonquin. The best fitting theoretical-uplift curve is consistent with a $50 \mathrm{~km}$ thick lithosphere.

\section{Discussion and conclusion}

The numerical results briefly described in the previous section show that the thickest lithosphere is associated with the exponential load of $4 \mathrm{~km}$ axial thickness under the assumption of isostatic equilibrium. The trade-off between the sharpness of

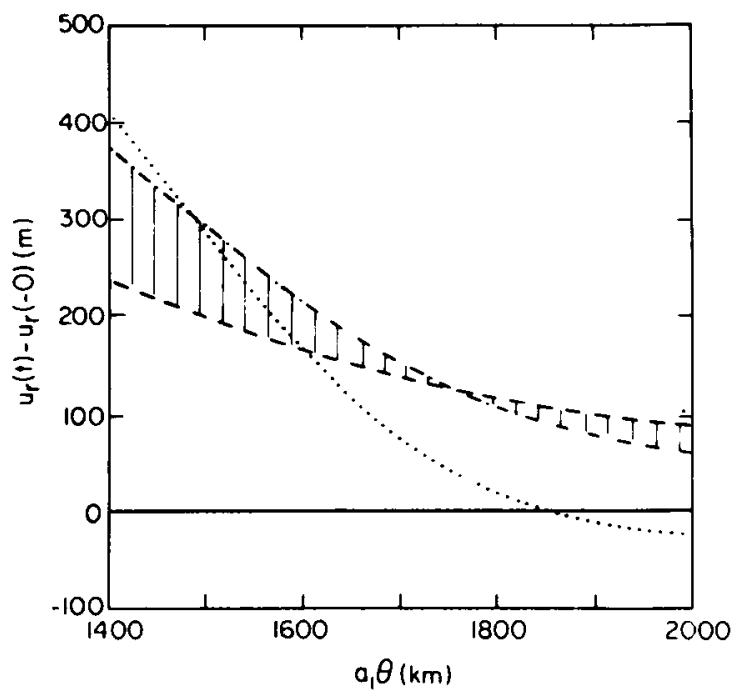

FIG. 6. Uplift since time $t=0$ of load removal as function of distance $a_{1} \theta$ from load axis at $t<0$ (solid), $t=1 \mathrm{ka}$ (dashed), $t=4$ ka (dot-dashed), or $t \rightarrow \infty$ (dotted); hatched area illustrates uplift for a strandline deposited at $t_{1}=1 \mathrm{ka}$ and observed at $t_{2}=4 \mathrm{ka}$.

the load edge and the thickness of the lithosphere has been mentioned in the previous section and needs no further comment. The result that maximum thickness estimates are associated with the assumption of equilibrium at $t_{1}$ and $t_{2}$ may deserve some explanation, however.

We consider Fig. 6, which shows the uplift $u_{\mathrm{r}}(t)-u_{\mathrm{r}}(-0)$ relative to the time $t=-0$ immediately before the instantaneous removal of a parabolic load of $1600 \mathrm{~km}$ radius and 4 $\mathrm{km}$ axial thickness. The lithosphere is $100 \mathrm{~km}$ thick; the other parameters are as before. It is assumed that equilibrium applies to $t<0$. Initially the relaxation is characterized by a large circular region of uplift. The upward movement has a maximum below the load axis but extends considerably into the peripheral region. This sympathetic movement of the central and peripheral regions is characteristic of deep-flow models (Cathles 1975, pp. 184-191). As relaxation continues, the area of uplift becomes more confined. Annular regions of subsidence encircle the deglaciated area at some distance and gradually move inward.

Since the uplift of a particular strandline is reckoned from the time of its deposition, it is obvious from Fig. 6 that the assumption of partial recovery of the Earth's surface before deposition $\left(t_{1}>0\right)$ or of incomplete recovery at the time of observation $\left(t_{2}<\infty\right)$ results in uplift curves of reduced slope and therefore in smaller thickness estimates for the lithosphere in the interpretation. By a similar argument it could be shown that the assumption of disequilibrium at the time of load removal also leads to uplift curves of reduced slope and thus again to smaller thicknesses.

Walcott's $(1970 a)$ theoretical model is characterized by both a sharp load edge and the assumption of equilibrium at the times of deposition and observation of the strandline. It therefore seems reasonable to interpret his estimate of lithospheric thickness as an upper bound. Using

[5] $D=\mu_{1} h_{1}^{3} /\left[6\left(1-v_{1}\right)\right]$

Walcott's estimate of $D=6 \times 10^{24} \mathrm{~N} \mathrm{~m}$, with a range from $3 \times 10^{24}$ to $2 \times 10^{25} \mathrm{~N} \mathrm{~m}$, can be converted into a thickness value. For $\mu_{1}=0.67 \times 10^{11} \mathrm{~N} \mathrm{~m}^{-2}$, which is typical of the 
Earth at $100 \mathrm{~km}$ depth (Bullen 1963, pp. 232-235), and $\nu_{1}=0.5$, i.e., incompressibility, we obtain $h_{1}=65 \mathrm{~km}$, with a range from 51 to $96 \mathrm{~km}$. This is much lower than the value of $125 \mathrm{~km}$ inferred in the previous section on the basis of essentially the same model (see Fig. 4a).

In order to explain this difference by a factor of about two, it must be noted that Walcott's (1970a) value reflects his choice of $2.7 \mathrm{~km}$ as the axial thickness of the model ice sheet. This is probably too low. In the present study the axial ice thickness has been fixed at $4 \mathrm{~km}$. This is slightly higher than the value of $3.75 \mathrm{~km}$ suggested by Cathles (1975, p. 126) or Paterson's (1972) estimate of $3.6 \mathrm{~km}$. It also exceeds the thickness adopted by $W u$ and Peltier (1982), who preferred $3.5 \mathrm{~km}$. The value of $4 \mathrm{~km}$ may therefore be regarded as an upper bound on load thickness, resulting in an upper bound on lithospheric thickness in the interpretation.

As mentioned previously, the exponential profile is not in agreement with theoretical considerations regarding the equilibrium shape of large ice sheets. It must be noted, however, that the Laurentide ice front is probably not in equilibrium when the Algonquin strandline was formed. If an upper bound on lithospheric thickness is required, results based on the steep exponential load profile therefore cannot be completely ignored. As an inspection of Fig. 4 demonstrates, the exponential load profile results in thickness estimates that are higher by about $25 \mathrm{~km}$ than those associated with the parabolic load.

If the negative free-air gravity anomaly in the region of the Laurentide glaciation centre (e.g., Walcott 1970a) is taken as an indication of incomplete relaxation, we are forced to exclude the assumption of isostatic equilibrium underlying Fig. 4. The amount of remaining uplift is, however, still under discussion. Peltier and $\mathrm{Wu}$ (1982) have pointed out that, if one permits second-order density jumps in the Earth model associated with the discontinuities in the Earth near 400 and $670 \mathrm{~km}$ depths, the mantle supports secondary modes of relaxation having relaxation times that are large compared with the major mode associated with the first-order density discontinuity across the Earth's surface. Whereas the internal modes are important for understanding the free-air gravity anomaly, their influence on relative-uplift observations is small. In the Earth model discussed here, internal modes are disregarded. Relaxation is nevertheless incomplete at $12 \mathrm{ka}$ after the initiation of unloading (cf. Figs. $4 b$ and $5 a$ ), and the thickness of the lithosphere is therefore more likely around $75 \mathrm{~km}$ or lower (Fig. 5 $b$ and $c$ ).

We therefore tentatively conclude that, assuming a parabolic load, the thickness of the lithosphere is constrained to be less than $75 \mathrm{~km}$ by the Algonquin strandline data. Our estimate is, however, contingent upon several conditions that are implicit in the model used here.

One of them is the assumption of a uniformly viscous mantle, which is probably only an approximation. The effect of increasing lower-mantle viscosity is to decrease predicted tilts (Wu and Peltier 1983). This obviously requires a reduction in lithospheric thickness in order that the data still be satisfied. Since we are concerned with imposing an upper bound on lithospheric thickness, this modification is of secondary importance to us.

Of some significance is, on the other hand, the assumption of an incompressible lithosphere. The errors introduced by neglecting compressibility can be estimated from [5]. We take $v_{1}=0.272$, which is typical of the Earth at $100 \mathrm{~km}$ depth. This increases the thickness estimate by $13 \%$ compared with incom- pressibility. We therefore adopt $h_{1}=85 \mathrm{~km}$ (parabolic load) and $h_{1}=110 \mathrm{~km}$ (exponential load) as improved upper bounds. These results largely confirm Walcott's (1970a) estimate of $D=6 \times 10^{24} \mathrm{~N} \mathrm{~m}$ for the flexural rigidity of the lithosphere, which, with $\mu_{1}=0.67 \times 10^{11} \mathrm{~N} \mathrm{~m} \mathrm{~m}^{-2}$ and $v_{1}=0.272$, approximately corresponds to $h_{1}=75 \mathrm{~km}$. In view of the different assumptions underlying his interpretation, this coincidence is somewhat fortuitous, however.

The estimates are, however, in conflict with Peltier's (1984) interpretation of deglaciation-induced relative-sea-level changes along the east coast of North America, which led him to infer a lithospheric thickness of approximately $200 \mathrm{~km}$ for the continent. In discussing possible explanations for this discrepancy we concentrate on the two main differences between the model used by Peltier and the model underlying the present study.

Our difference is related to the modelling of the Laurentide ice sheet, which is represented by a finite-element model in Peltier (1984), whereas it is approximated by a circular cap load here. Although realistic load models, such as ICE-2 (Wu and Peltier 1983), are required for global studies, the adjustment data from a particular site near the ice margin should be explicable using a much simpler load representation. This is a consequence of the fact that the magnitude of the tilt is most strongly influenced by nearby loads (e.g., Wolf 1984a). In the present study the controlling feature is obviously the shape of the ice margin. It can therefore probably be excluded that the different thickness estimates reflect the different load models employed.

More significant could perhaps be perturbations of the geoid, which have been neglected here. The perturbations can be separated into contributions from the externally applied gravity field ("load") and from internal mass redistributions caused by the load. So far the importance of these effects has mostly been discussed in connection with relative uplift (Farrell and Clark 1976; Clark et al. 1978; Peltier et al. 1978). Recently Wu and Peltier (1982) have shown quantitatively that the effects of geoid perturbations on predicted relative-sea-level variations are significant at sites near the ice margin and for times earlier than about $8 \mathrm{ka} \mathrm{BP}$.

Clark (1980) pointed out that the tilt of proglacial strandlines with respect to the present-day geoid reflects the radial displacement of the Earth's surface and the change of the geoid since strandline deposition. Clearly, the mutual attraction between the Earth and the Pleistocene ice sheets must have been such that the geoid was raised near the loads. Then some fraction of the presently observed tilt of the Algonquin strandline must be related to this ancient gravitational perturbation. If corrections for geoid changes are applied to the theoreticaluplift curves of Figs. 4 and 5, their slopes are reduced and larger lithospheric thicknesses become consistent with the data. The magnitude of this effect compared with the drastic changes in predicted slope produced by steepening the load profile (Fig. 3) is, however, not yet clear. A quantitative analysis of the geoidal deformations caused by the Laurentide ice sheet is therefore recommended.

\section{Acknowledgments}

This study has been financially supported by a Natural Sciences and Engineering Research Council of Canada Postgraduate Scholarship. Discussions with Richard Peltier have been very helpful. Constructive criticism by an anonymous reviewer is gratefully acknowledged. 
BROECKER, W. S. 1966. Glacial rebound and the deformation of the shorelines of proglacial lakes. Journal of Geophysical Research, 71. pp. 4777-4783.

BRotCHIE, J. F., and SILVESTER, R. 1969. On crustal flexure. Journal of Geophysical Research, 74, pp. 5240-5252.

BuLlen, K. E. 1963. An introduction to the theory of seismology. 3rd ed. Cambridge University Press, Cambridge, England.

Cathles, L. M. 1975. The viscosity of the Earth's mantle. Princeton University Press, Princeton. NJ.

Chapman, L. J. 1954. An outlet of Lake Algonquin at Fossmill, Ontario. Proceedings of the Geological Association of Canada, 6 , pp. 61-68.

ClARK, J. A. 1980. The reconstruction of the Laurentide ice sheet of North America from sea level data: method and preliminary results. Journal of Geophysical Research, 85. pp. 4307-4323.

Clark, J. A., Farrell, W. E., and Peltier, W. R. 1978. Global changes in postglacial sea level: a numerical calculation. Quaternary Research, 9, pp. 265-287.

FarRell, W. E., and Clark, J. A. 1976. On postglacial sea level. Geophysical Journal of the Royal Astronomical Society, 46, pp. 647-667.

Nakiboglu, S. M., and LAmBECK. K. 1982. A study of the Earth's response to surface loading with application to Lake Bonneville. Geophysical Journal of the Royal Astronomical Society, 70, pp. 577-620.

PATERSON, W. S. B. 1972. Laurentide ice sheet. Estimated volumes during late Wisconsin. Reviews of Geophysics and Space Physics, 10, pp. 885-917.

1981. The physics of glaciers. 2nd ed. Pergamon Press, Oxford, England.

PEltier, W. R. 1982. Dynamics of the ice age Earth. Advances in Geophysics, 24, pp. 1-146.
1984. The thickness of the continental lithosphere. Journal of Geophysical Research, 89, pp. II $303-11316$.

Peltier. W. R., and ANDREwS, J. T. 1976. Glacial isostatic adjustment. I. The forward problem. Geophysical Joumal of the Royal Astronomical Society. 46, pp. 605-646.

Peltier, W. R., and WU, P. 1982. Mantle phase transitions and the free air gravity anomalies over Fennoscandia and Laurentia. Geophysical Research Letters. 9. pp. 731-734.

Peltier, W. R., Farrell. W. E.. and Clark. J. A. 1978. Glacial isostasy and relative sea level: a numerical calculation. Tectonophysics, 50. pp. 81-110.

PREST. V. K. 1969. Retreat of Wisconsin and Recent ice in North America. Geological Survey of Canada, Map No. 1257A. Scale 1:5000 000 .

WALCOTT. R. I. 1970a. Isostatic response to loading of the crust in Canada. Canadian Journal of Earth Sciences. 7, pp. 716-727.

$1970 \mathrm{~b}$. Flexural rigidity. thickness, and viscosity of the lithosphere. Journal of Geophysical Research, 75. pp. 3941-3954.

WOLF, D. 1984a. On the relation between two-dimensional and axisymmetric loads in plate flexure problems. Journal of Geophysics. 54. pp. 232-235.

1984b. The relaxation of spherical and flat Maxwell Earth models and effects due to the presence of the lithosphere. Journal of Geophysics, 56, pp. 24-33.

1985. The normal modes of a uniform. compressible Maxwell half-space. Journal of Geophysics. (In press.)

Wu, P., and PELtiER, W. R. 1982. Viscous gravitational relaxation. Geophysical Journal of the Royal Astronomical Society. 70. pp. 435-485.

1983. Glacial isostatic adjustment and the free air gravity anomaly as a constraint on deep mantle viscosıty. Geophysical Journal of the Royal Astronomical Society, 74, pp. 377-449. 